International Journal of Current Microbiology and Applied Sciences

ISSN: 2319-7706 Volume 6 Number 7 (2017) pp. 2069-2076

Journal homepage: http://www.ijcmas.com

Original Research Article

https://doi.org/10.20546/ijcmas.2017.607.244

\title{
Genetic Diversity Analysis in Sunflower (Helianthus annuus L.) parental Lines Using SSR and RAPD Markers
}

\author{
P.G. Suresha ${ }^{1}$, Vikas V. Kulkarni ${ }^{2}$, S.M. Supriya ${ }^{1}$, S. Darshan ${ }^{3 *}$ and \\ Chandrashekar B. Patil ${ }^{1}$ \\ ${ }^{1}$ Department of Genetics and Plant Breeding, College of Agriculture, \\ Raichur, Karnataka, India -584 104 \\ ${ }^{2}$ AICRP on Sunflower, MARS, University of Agricultural Sciences, \\ Raichur, Karnataka, India-584 104 \\ ${ }^{3}$ Department of Plant Breeding and Genetics, College of Agriculture, \\ Vellayani, Kerala, India-695 522 \\ *Corresponding author
}

A B S T R A C T

Using molecular markers one can examine genetic diversity of species, cultivars, lines and forms of sunflower, identify genotypes, systematize collection material,

Keywords

Sunflower,

Diversity analysis, SSR, RAPD.

Article Info

Accepted:

21 June 2017

Available Online:

10 July 2017 classify heterosis groups and construct genetic maps. Fourteen parental genotypes of sunflower viz.,CMS-2A, CMS-821A, CMS-850A, R-10-46-2A, CMS-A4, CMS-A6, CMS-A10, R-GM-39, R-GM-41, R-GM-49, R-GM-69, 83-Br, R-393 and R2F01120B were analyzed for genetic diversity using 15 RAPD and 44 SSR primers. The genetic similarity index computed considering pooled data of SSR and RAPD markers showed very wide range from 0.18 to 0.74 indicating high variability among 14 sunflower genotypes. The dendrogram separated 14 sunflower genotypes into four main clusters. The first cluster A having genetic similarity index of 0.64 included three sunflower genotypes (CMS 2A,CMS $821 \mathrm{~A}$ and CMS A4) indicating the narrow genetic base, however cluster B showed sufficient genetic diversity among four sunflower genotypes R-GM-49, R-GM-69, R-GM-41 and R-393 as these restorer lines have been derived from different genetic background.

\section{Introduction}

Sunflower belongs to the genus Helianthus of the family Asteraceae, tribe Heliantheae, sub tribe Helianthinae, which includes 20 genera with 400 species. Helianthus annuus L. is an important oilseed crop that produces edible oil. In India, Sunflower is being grown over an area of 0.55 million hectares with a production of 0.42 million tonnes. Presently, Karnataka is the leading state in the country contributing 64.35 and 51.08 per cent to total area and production, respectively and it is the second important oilseed crop after groundnut in the state having an area of 0.36 million hectares with production of 0.21 million tonnes. However, productivity $\left(597 \mathrm{~kg} \mathrm{ha}^{-1}\right)$ is lesser than the national average of $752 \mathrm{~kg} \mathrm{ha}^{-1}$ (Anonymous, 2016). 
In India, it is an important source of edible and nutritious oil. It is a rich source of edible oil (40-52\%) and considered as good quality oil from health point of view due to presence of polyunsaturated fatty acids with 55-60 per cent of linoleic acid and 25-30 per cent of oleic acid which are known to reduce the risk of cardiac related problems.

Molecular markers played a major role in identifying variation in genomic DNA sequences. Polymorphism at molecular level in different crop species have contributed to assess genetic diversity, reconstruct accurate phylogenetic relationships and transferring of particular traits. The invention of the polymerase chain reaction (PCR) to amplify short segments of DNA gave rise to second generation of faster and less expensive PCRbased markers. Among the available methods, randomly amplified polymorphic DNA (RAPD) and simple sequence repeats (SSR) have been most widely used for diversity studies, DNA fingerprinting, map construction and linkage analysis. It involves use of short random sequences of oligonucleotides as primers for amplification of randomly selected segments of the target genome. Utilization of molecular marker based genetic distance for predicting hybrid heterosis has been of great interest to breeders. The efficiency of hybrid breeding programs could be increased if the inbred lines per se could be screened and the superior crosses predicted before field evaluation (Melchinger et al., 1990).

\section{Materials and Methods}

\section{Plant material}

Fourteen parental genotypes of sunflower viz.,CMS-2A, CMS-821A, CMS-850A, R-1046-2A, CMS-A4, CMS-A6, CMS-A10, RGM-39, R-GM-41, R-GM-49, R-GM-69, 83$\mathrm{Br}, \mathrm{R}-393$ and R2F01120B were analyzed for genetic diversity using 15 RAPD and 44 SSR primers (Table 1).

\section{DNA extraction procedure}

Genomic DNA was isolated from young leaves from each genotype following the Cetyl Trimethyl Ammonium Bromide (CTAB) method of Saghai Maroof et al., (1984) with slight modifications. RNA was removed from the DNA preparation by adding $10 \mu \mathrm{l}$ of RNAase $(10 \mathrm{mg} / \mathrm{ml})$ and then incubated for $30 \mathrm{~min}$ at $37^{\circ} \mathrm{C}$. The concentration of DNA was estimated spectrophotometrically and also by gel electrophoresis using 0.8 per cent agarose with known concentrations of DNA and suitable dilutions was made for amplification.

\section{SSR and RAPD Analysis}

Forty four Simple Sequence Repeat (SSR) and fifteen random oligonucleotide (RAPD) primers were tested in this experiment to amplify the template DNA.The RAPD and SSR reaction mixture consisted of 25-50-ng of template DNA, 5-pM of random decamer primer, 25-mM MgCl2, 2.5-mM of dNTPs, 1unit of Taq polymerase, 10-x Taq buffer in a volume of $20-\mu 1$ contents.

\section{Thermal cycling}

Sterile microfuge tubes were numbered from 1 to $45,1.0 \mu \mathrm{l}$ of template DNA from individual parental genotypes was added to each tube. $20 \mu \mathrm{l}$ of master mix was added to all the tubes and was given a short spin to mix the contents. The tubes were placed in the thermal cycler for amplification. The PCR reaction was carried out using master cycler gradient 5331 Eppendorf version 2.30-31-09, Germany, with the following specification: For SSR, initial denaturation for 5 minutes at $95^{\circ} \mathrm{C}, 35$ cycles of 1 minute at $94^{\circ} \mathrm{C}$ (denaturation), 1 minute at $23-65^{\circ} \mathrm{C}$ (Based on 
primer annealing temperature) and 2 minutes at $72^{\circ} \mathrm{C}$ (primer extension), 10 minutes at $72^{\circ} \mathrm{C}$ (final extension), then followed by a final hold at $4^{\circ} \mathrm{C}$, for RAPD, initial denaturation for 5 minutes at $95^{\circ} \mathrm{C}, 35$ cycles of 1 minute at $94^{\circ} \mathrm{C}$ (denaturation), 1 minute at $40^{\circ} \mathrm{C}$ and 2 minutes at $72^{\circ} \mathrm{C}$ (primer extension), 10 minutes at $72^{\circ} \mathrm{C}$ (final extension), then followed by a final hold at $4^{\circ} \mathrm{C}$.

\section{Electrophoresis}

Technique of agarose gel was used for separation and quantification of amplified product. Agarose of $1.2 \mathrm{~g}$ for RAPD and $3.5 \mathrm{~g}$ for SSR was weighed and added to a conical flask separately containing $100 \mathrm{ml}$ of $1 \mathrm{x}$ TAE buffer. The agarose was melted by heating the solution on an electric heater and the solution was stirred to ensure even mixing and complete dissolution of agarose.

The solution was then cooled to about 40-45 C. Two to three drops of ethidium bromide $\left(0.5 \mu \mathrm{g} \mathrm{ml}^{-1}\right)$ were added. The solution was poured into the pre levelled gel casting platform after inserting the comb in the trough. While pouring, sufficient care was taken for not allowing the air bubbles to trap in the gel.

The gel was allowed to solidify and the comb was removed after placing the solidified gel into the electrophoretic apparatus containing sufficient tank buffer ( $1 \mathrm{x}$ TAE) so as to cover the well completely. The amplified products $(25 \mu \mathrm{l})$ to be analyzed were carefully loaded along with the marker, into the sample wells, after adding 2-3 $\mu \mathrm{l}$ of loading dye (Bromophenol blue) with the help of a micropipette. Electrophoresis was carried out at 60-65 volts, until the tracking dye migrated to the end of the gel. Ethidium bromide stained DNA bands were viewed under gel documentation and Photograph was taken.

\section{Analysis of amplified profiles}

Amplified fragments were scored as ' 1 ' for the presence and ' 0 ' for the absence of band generating the 0 and 1 matrix and per cent polymorphism was calculated by using the following formula. The binary data were used to compute pair wise similarity coefficient (Jaccard, 1908). A dendrogram based similarity co-efficient was generated by using the weighted pair group of arthimetic means (UPGMA) (Fig. 3).

Number of polymorphic bands

Per cent polymorphism = ---------------- $\mathrm{x} 100$

Total number of bands

\section{Results and Discussion}

Identification of sunflower cultivars, lines and hybrids is mainly based on morphological traits which were among the earliest markers used in germplasm management (Stanton et al., 1994) despite a number of limitations, including low polymorphism, low heritability, late expression, vulnerability to environmental influences (Smith, and Smith, 1992; Konarev, 2000), and morphological data cannot provide reliable information of calculation of genetic distance in term validation of pedigree.

This, in turn may affect the estimation of genetic relationships. However, if the traits are highly heritable, morphological markers are one of the choices for diversity studies because the inheritance of the marker can be monitored visually (Yoseph 2005). Despite the problems associated with this method, it continues to play a major role in studying and characterizing germplasm since it requires no complicated laboratory facilities and procedures.

So that molecular markers can be used as valuable tool for identification of parental 
lines and varieties, also helps in studying the evolutionary/phylogenetic relationship between plant varieties.

To define the phylogenetic relationship between 14 sunflower genotypes (seven CMS lines and seven $\mathrm{R}$ lines), 44 SSR markers and 15 RAPD markers were used in present study. Genetic similarity of sunflower genotypes was calculated using Jaccard's similarity coefficient by analysing 44 SSR and 15 RAPD markers data (Table 3). These similarity coefficients were used to generate dendrogram by UPGMA analysis in order to determine the grouping of different genotypes. Among 44 SSR primers, three primers showed the polymorphism, 35 primers showed monomorphic bands and six primers failed to amplify bands. The ORS337 primer showed the polymorphism at 195 base pairs, while ORS-337 and ORS-358 showed polymorphism at 185 and 320 base pairs, respectively (Fig. 2).

Out of 15 RAPD primers, 13 primers showed polymorphism whereas remaining 2 primers did not amplify. Thirteen amplified primers showed a high DNA polymorphism among the 14 parental genotypes. Thirteen primers produced a total of 310 amplified products, among them 73 were polymorphic with an average of 23.52 per cent polymorphism (Table 2).

Fig.1 Dendrogram showing the genetic similarity among 14 sunflower genotypes as derived by RAPD and SSR markers

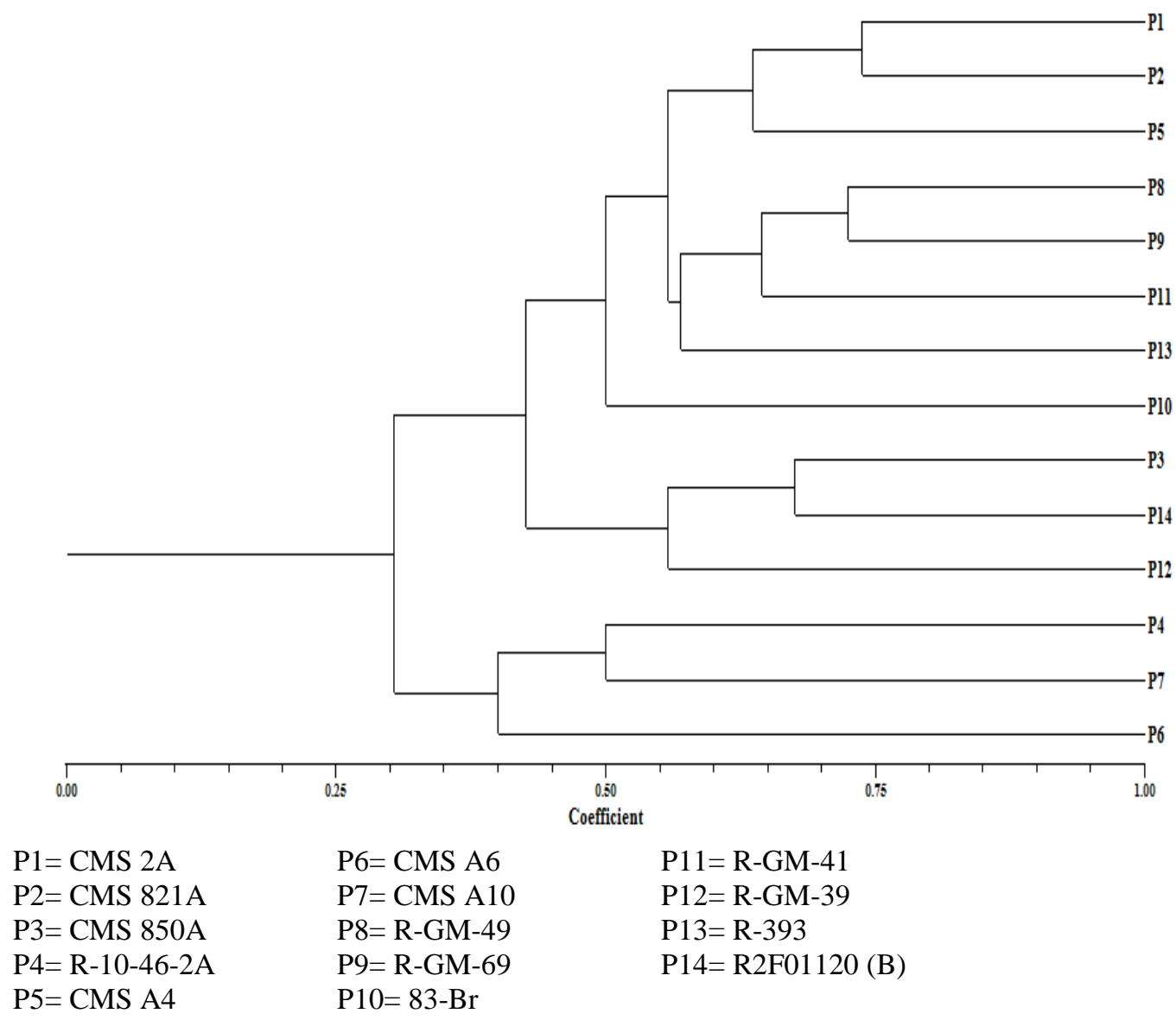


Fig.2 SSR banding pattern of sunflower parental genotypes
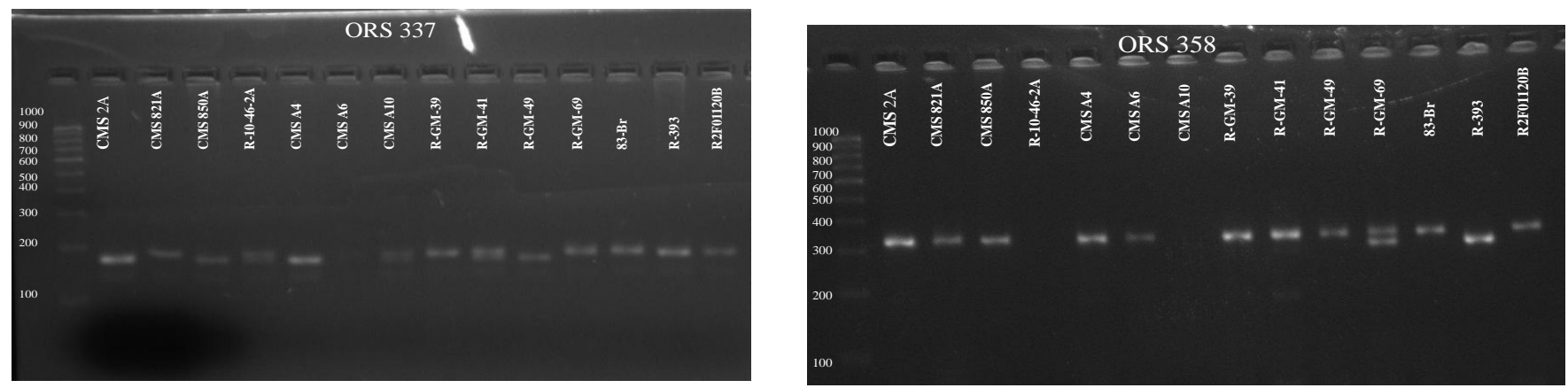

Fig.3 RAPD banding pattern of suntlower parental genotypes
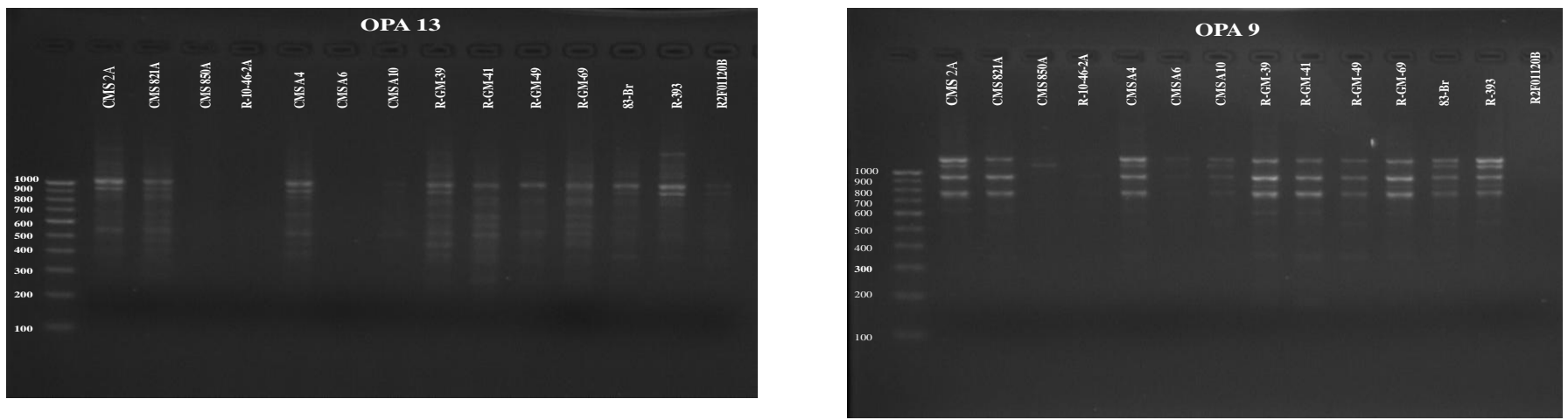

Table.1 List of RAPD and SSR primers used for analysis of 14 sunflower genotypes

\begin{tabular}{|c|c|c|}
\hline \multicolumn{3}{|c|}{ RAPD primers } \\
\hline 1. OPA-01 & 6. OPA-06 & 11. OPA-11 \\
\hline 2. OPA-02 & 7. OPA-07 & 12. OPA-12 \\
\hline 3. OPA-03 & 8. OPA-08 & 13. OPA-13 \\
\hline 4. OPA-04 & 9. OPA-09 & 14. OPA-14 \\
\hline 5. OPA-05 & 10. OPA-10 & 15. OPA-15 \\
\hline \multicolumn{3}{|c|}{ Sunflower SSR primers } \\
\hline 1. ORS-287 & 16. ORS-324 & 31. ORS-677 \\
\hline 2. ORS -290 & 17. ORS-332 & 32. ORS-769 \\
\hline 3. ORS-296 & 18. ORS-333 & 33. ORS-780 \\
\hline 4. ORS-300 & 19. ORS-339 & 34. ORS- 807 \\
\hline 5. ORS-301 & 20. ORS-337 & 35. ORS- 811 \\
\hline 6. ORS-309 & 21. ORS-358 & 36. ORS- 852 \\
\hline 7. ORS-310 & 22. ORS-378 & 37. ORS- 930 \\
\hline 8. ORS-311 & 23. ORS-388 & 38. ORS- 938 \\
\hline 9. ORS-315 & 24. ORS-407 & 39. ORS- 959 \\
\hline 10 ORS-316 & 25. ORS- 484 & 40. ORS- 1068 \\
\hline 11.ORS-318 & 26. ORS-546 & 41. ORS- 1088 \\
\hline 12. ORS-319 & 27. ORS-552 & 42. ORS- 1159 \\
\hline 13 ORS-321 & 28. ORS-578 & 43. ORS- 1220 \\
\hline 14.ORS-322 & 29. ORS- 628 & 44. ORS- 1245 \\
\hline 15.ORS-323 & 30. ORS- 671 & \\
\hline
\end{tabular}


Table.2 Analysis of RAPD banding pattern for sunflower parental genotypes

\begin{tabular}{|c|c|c|c|c|c|}
\hline Sl. No. & Primer & Total No. of DNA fragments produced & No. of polymorphic fragments & No. of monomorphic fragments & Per cent polymorphism \\
\hline & OPA 1 & 20 & 4 & 16 & 20.00 \\
\hline 2 & OPA 2 & 31 & 7 & 24 & 22.58 \\
\hline 3 & OPA 3 & 0 & 0 & 0 & 0.00 \\
\hline 4 & OPA 4 & 30 & 8 & 22 & 26.67 \\
\hline 5 & OPA 5 & 12 & 2 & 10 & 16.67 \\
\hline 6 & OPA 6 & 0 & 0 & 0 & 0.00 \\
\hline 7 & OPA 7 & 37 & 7 & 30 & 18.92 \\
\hline 8 & OPA 8 & 4 & 2 & 2 & 50.00 \\
\hline 9 & OPA 9 & 35 & 5 & 30 & 14.29 \\
\hline 10 & OPA 10 & 21 & 7 & 14 & 33.33 \\
\hline 11 & OPA 11 & 29 & 6 & 23 & 20.69 \\
\hline 12 & OPA 12 & 22 & 7 & 15 & 31.82 \\
\hline 13 & OPA 13 & 37 & 8 & 29 & 21.62 \\
\hline 14 & OPA 14 & 10 & 4 & 6 & 40 \\
\hline \multirow[t]{3}{*}{15} & OPA 15 & 22 & 6 & 16 & 27.27 \\
\hline & Total & 310 & 73 & 237 & - \\
\hline & Average & 20.66 & 4.86 & 15.8 & 23.52 \\
\hline
\end{tabular}

Table.3 Jaccard similarity coefficient among 14 sunflower genotypes as revealed by RAPD and SSR marker analysis

\begin{tabular}{|c|c|c|c|c|c|c|c|c|c|c|c|c|c|c|}
\hline & CMS 2A & CMS 821A & CMS 850A & $\mathrm{R}-10-46-2 \mathrm{~A}$ & CMS A4 & CMS A6 & CMS A10 & R-GM-49 & R-GM-69 & $83-\mathrm{Br}$ & R-GM-41 & R-GM-39 & R-393 & R2F01120 (B) \\
\hline CMS 2A & 1.00 & & & & & & & & & & & & & \\
\hline CMS 821A & 0.74 & 1.00 & & & & & & & & & & & & \\
\hline CMS 850A & 0.41 & 0.42 & 1.00 & & & & & & & & & & & \\
\hline R-10-46-2A & 0.21 & 0.24 & 0.47 & 1.00 & & & & & & & & & & \\
\hline CMS A4 & 0.66 & 0.61 & 0.43 & 0.20 & 1.00 & & & & & & & & & \\
\hline CMS A6 & 0.21 & 0.24 & 0.42 & 0.40 & 0.27 & 1.00 & & & & & & & & \\
\hline CMS A10 & 0.33 & 0.33 & 0.52 & 0.50 & 0.36 & 0.40 & 1.00 & & & & & & & \\
\hline R-GM-49 & 0.54 & 0.53 & 0.32 & 0.19 & 0.55 & 0.18 & 0.29 & 1.00 & & & & & & \\
\hline R-GM-69 & 0.52 & 0.56 & 0.39 & 0.21 & 0.52 & 0.20 & 0.31 & 0.72 & 1.00 & & & & & \\
\hline $83-\mathrm{Br}$ & 0.43 & 0.44 & 0.49 & 0.26 & 0.53 & 0.28 & 0.40 & 0.52 & 0.52 & 1.00 & & & & \\
\hline R-GM-41 & 0.59 & 0.57 & 0.36 & 0.18 & 0.61 & 0.20 & 0.30 & 0.63 & 0.66 & 0.53 & 1.00 & & & \\
\hline R-GM-39 & 0.43 & 0.48 & 0.55 & 0.28 & 0.55 & 0.33 & 0.48 & 0.44 & 0.44 & 0.51 & 0.49 & 1.00 & & \\
\hline R-393 & 0.58 & 0.51 & 0.52 & 0.24 & 0.61 & 0.26 & 0.42 & 0.53 & 0.60 & 0.54 & 0.58 & 0.56 & 1.00 & \\
\hline R2F01120 (B) & 0.34 & 0.38 & 0.68 & 0.31 & 0.39 & 0.42 & 0.46 & 0.27 & 0.33 & 0.47 & 0.36 & 0.57 & 0.46 & 1.00 \\
\hline
\end{tabular}


The OPA8 primer showed highest viz., 50 per cent polymorphism, followed by OPA14 (40 $\%)$ and OPA10 (33.33\%) whereas, the primer OPA9 showed least polymorphism (14.29\%) compared to others. The number of bands ranged from 4 (OPA8) to 37 (OPA7 and OPA13) with an average of 20.66 bands per primer and 4.86 bands per primer were polymorphic (Fig. 3).

\section{Similarity index}

The similarity coefficient for most of the genotypes ranged from 0.20 to 0.74 . The highest similarity observed between the parental genotype CMS 821A and CMS 2A (0.74) while the lowest similarity was observed between the parental genotypes viz., R-GM-41 and R-10-46-2A (0.18), R-GM-49 and CMS A6 (0.18).

The genetic similarity computed considering pooled data of SSR and RAPD markers showed very wide range from 0.18 to 0.74 indicating the presence of high variability among 14 sunflower genotypes. Similar results were reported by Erasmus (2008) and Popov et al., (2002).

The maximum similarity observed between CMS 2A and CMS 821A (0.74) as these lines have been developed at one breeding centre. On the basis of SSR and RAPD pooled data their genetic base look very narrow. In the present study it was observed that the genotype $83-\mathrm{Br}$ occupied a unique position and was more diverse from rest of 13 genotypes whereas CMS A6 occupied distinct and unique position from rest of the 13 sunflower genotypes, indicating most diverse genetic makeup.

The sunflower genetic diversity and coancestry analysis have been carried out using RAPD (Arias et al., 1995). The placement of individual cultivars into different accessions based on morphological attributes doesn't necessarily reflect real genetic relationship. RAPD have primarily been used for tagging phenotypic loci in sunflower e.g., resistance genes against rust (Puccinia helianthi schw) and Orobanche cumana wallr (Lawson et al., 1998; Lu et al., 2000).

\section{Clusters analysis}

The dendrogram based on RAPD and SSR data separated 14 sunflower genotypes into four main clusters- A, B, C and D (Fig. 1). The first cluster-A includes CMS 2A, CMS 821A and CMS A4 with a genetic identity ranging from 0.64 to 0.73 .

The cluster-B revealed sufficient amount of genetic diversity including four genotypes RGM-49, R-GM-69, R-GM-41 and R-393 with a similarity ranging from 0.58 to 0.73 . The cluster-C includes CMS 850A, R2F01120 (B) and R-GM-39 with a genetic identity ranging from 0.56 to 0.68 . The cluster-D includes R10-46-2A, CMS A10 and CMS A6 with a similarity ranging from 0.40 to 0.50 .

Cluster A having genetic similarity of 0.64 included three sunflower genotypes (CMS 2A,CMS $821 \mathrm{~A}$ and CMS A4) indicating the narrow genetic base, however cluster B showed sufficient genetic diversity among four sunflower genotypes R-GM-49, R-GM69, R-GM-41 and R-393 as these restorer lines have been derived from different genetic background.

In conclusion, the genetic similarity index based on SSR and RAPD markers pooled data ranged from 0.18 to 0.74 indicating high variability among 14 sunflower genotypes.

The molecular diversity analysis grouped 14 sunflower parents in four main clusters. These genotypes can be utilized in future breeding programmes. 


\section{References}

Anonymous, 2016, Annual Group Meeting on Sunflower, Director's report, ICARIndian Institute of Oilseeds Research.

Arias, D. M. and Reiseberg, L. H., 1995, Genetic relationship among domesticated and wild sunflower (Helianthus annuus, Asteraceae). Economical Botany, 49: 239-248.

Erasmus, T. E., 2008, Genetic Diversity of Proprietary Inbred Lines of Sunflower, Determined by Mapped SSR Markers and Total protein analysis. Ph.D. Thesis, Univ. of KwaZulu Natal, Pietermaritzburg.

Jaccard, P., 1908, Nouvelles researches sur la distribution florale. Bull. Soc. Vaud. Sci. Nat., 44: 223-270.

Konarev, V.G., 2000. Cultivar identification and gene pool registration by seed proteins in cultivated plants. St. Petersburg: Vses. Inst. Rastenievod, Russia.

Lawson, W. R., Henry, R. J., Kochman, J. K. and Kong, G. A., 1994, Genetic diversity in sunflower (Helianthus annuus L.) as revealed by random amplified polymorphic DNA analysis. Australian J. Agric. Res., 45: 13191327.

Lu, Y. H., Melero-Vara, J. M., Garcia-Tejada, J. A. and Blanchard, 2000, Development of SCAR markers linked to the gene $\operatorname{Or} 5$ conferring rust resistance to broomrape (Orobanche cumana Wallr.) in sunflower. Theor. And Appl. Genet., 100: 625-632.

Melchinger, A. E., Lee, M. L., Amkey, K. R. and Woodman, W. W., 1990, Genetic diversity for restriction fragments length polymorphisms: relation to genetic effects in maize inbreds. Crop Sci., 30:1033-1040.

Popov, V. N., Urbanovich, O.Y. and Kirichenko, V. V., 2002, Studying Genetic diversity in inbred sunflower lines by RAPD and isozyme analyses. Russ. J. Genet., 38 (7): 785-790.

Saghai Maroof K., Soliman, M., Jorgensen, R. A. and Allard, R.W., 1984, Ribosomal DNA spacer-length polymorphisms in barley: Mendelian inheritance, chromosomal location, and population dynamics. Proc. Nat. Acad Sci., USA, 81: 8014- 8018.

Smith, J. S.C. and Smith, O. S., 1992. Fingerprinting crop varieties. Adv. Agron., 47: 85-140.

Stanton, M.A., Stewart, J. M., Percival, A. E. And Wandel, J. F., 1994. Morphological diversity and relationships in A-genome cottons, Gossypium arboreum and Gossypium herbaceum. Crop Sci., 34: 519-527.

Yoseph, B., 2005. Genetic analysis of traditional Ethiopian highland maize (Zea mays L.) using molecular markers and morphological traits: implication for breeding and conservation. Dissertation, University of Pretoria.

\section{How to cite this article:}

Suresha, P.G., Vikas V. Kulkarni, S.M. Supriya, S. Darshan and Chandrashekar B. Patil. 2017. Genetic Diversity Analysis in Sunflower (Helianthus annuиs L.) Parental Lines Using SSR and RAPD Markers. Int.J.Curr.Microbiol.App.Sci. 6(7): 2069-2076. doi: https://doi.org/10.20546/ijcmas.2017.607.244 